\title{
Analytic quantification of solar lentigines lightening by a $2 \%$ hydroquinone-cyclodextrin formulation
}

\author{
L Petit, GE Piérard* \\ Department of Dermatopathology, University Medical Center Sart Tilman, B-4000 Liège, Belgium. ${ }^{\star}$ Corresponding author, tel. +3243662408 , \\ fax+32 4 3662976, E-mail: Gerald.Pierard@ulg.ac.be
}

\begin{abstract}
Background The innate melanin pigmentation of skin is modulated during lifetime by a series of factors, including ageing and chronic ultraviolet light exposure. Actinic lentigines may be of particular concern from a cosmetic point of view. Conventional hypopigmenting agents are usually deceptive. Using cyclodextrins to form inclusion compounds with these agents might represent a more active drug delivery system.

Objective To assess sensitive and objective methods predicting the effects of a $2 \%$ hydroquinone-cyclodextrin formulation on solar lentigines.

Study design Thirty Asian adults applied a $2 \%$ hydroquinone-cyclodextrin formulation once daily on solar lentigines of a forearm for 2 months. The other untreated forearm served as a control. Monthly assessments were performed using skin colorimetry and fluorescence video recording combined with image analysis. Corneomelametry following photodensitometry of cyanoacrylate skin surface strippings was performed after melanin staining of the samples.

Results The control untreated solar lentigines showed no significant variations in the biometrological parameters. By contrast, the test formulation induced lightening of the solar lentigines. Corneomelametry disclosed improvement after 1 months' treatment, whereas the other assessments only reached significance after 2 months.

Conclusions A $2 \%$ hydroquinone-cyclodextrin formulation proved to be effective in lightening actinic lentigines. Corneomelametry predicted the effects discernible at a later stage by in vivo colour assessments of the melanin content.
\end{abstract}

Key words: hydroquinone, hypopigmenting agent, solar lentigo, ultraviolet light

Received: 16 September 2001, accepted 22 November 2002

\section{Introduction}

Macular melanoderma is one of the most disturbing features that may develop on chronically sun-exposed skin. The darkened age spots corresponding to solar lentigines and seborrhoeic keratoses are common skin lesions for the middle-aged and elderly, ${ }^{1,2}$ but are more frequent and of particular concern for those of Asian origin. ${ }^{3-7}$ They indeed detract from overall skin appearance and they may be perceived as a disturbing disfigurement.

Hydroquinone is a time-honoured hypopigmenting agent. It downregulates the multistep enzymatic process of melanin synthesis. ${ }^{8-10}$ Visual assessments were often used to assess skin lightening effects. Image analysis can be implemented to clinical video recording under white light ${ }^{7}$ or ultraviolet light illumination. 6,11 Corneomelametry is another tool allowing quantification of melanin deposits in the stratum corneum alone. ${ }^{6}$ The efficacy of most skin lighteners is weak on solar lentigines. ${ }^{6,7}$ Enhancing their bioavailability would be welcome in some instances. This could be achieved by cyclodextrins. These compounds are torus-shaped molecules that have the remarkable ability to form molecular inclusion compounds with a wide range of molecules. ${ }^{12}$ Penetration of some pharmaceutical actives can thus be enhanced.

The aim of the present study was to evaluate objective methods assessing the effects of a topically applied $2 \%$ 
hydroquinone-cyclodextrin formulation on actinic lentigines in Asian subjects.

\section{Subjects and methods}

A total of 22 women and eight men of Vietnamese ascent, aged from 41 to 57 years ( $49 \pm 4$ years) were enrolled in the single blind randomized intraindividual study. They were phototype III and they presented with solar lentigines on the forearms and hands. Dermoscopy was used to diagnose and select the target lesions. The volunteers applied the $2 \%$ hydroquinonecyclodextrin formulation once daily for 2 months to one forearm, the other forearm serving as an untreated control.

Comparative assessments were performed at baseline, and after 1 and 2 months of treatment. Three methods were used concurrently. The overall skin colour was assessed by narrowband spectrophotometry. The cumulative melanin load in the epidermis was evaluated using video image analysis under ultraviolet light illumination. The melanin content in the stratum corneum was quantified by corneomelametry.

Reflectance narrow-band spectrophotometric measurements were performed as previously described ${ }^{13,14}$ using the Mexameter $^{\circledast}$ (CK Electronic, Cologne, Germany). Three measurements of the erythema (E) and melanin (M) indices were performed on each target lesion. Their median values were considered for further calculations. Similar measurements were performed on the normal looking skin at $1 \mathrm{~cm}$ from the pigmented lesions. The differential $\mathrm{E}$ and $\mathrm{M}$ were calculated as the difference between the median values of both $\mathrm{E}$ and $\mathrm{M}$ of the lesional and non-lesional skin on each forearm.

Image analysis was performed using a video camera equipped with an internal ultraviolet light emitting unit (Visioscan ${ }^{\circledR}, \mathrm{CK}$ Electronic). This device allows to determine the relative area (\%) of infraclinical to clinically visible melanoderma.6,11,15 The contrast between hyperpigmented areas and the surrounding skin is indeed increased (fig. 1).

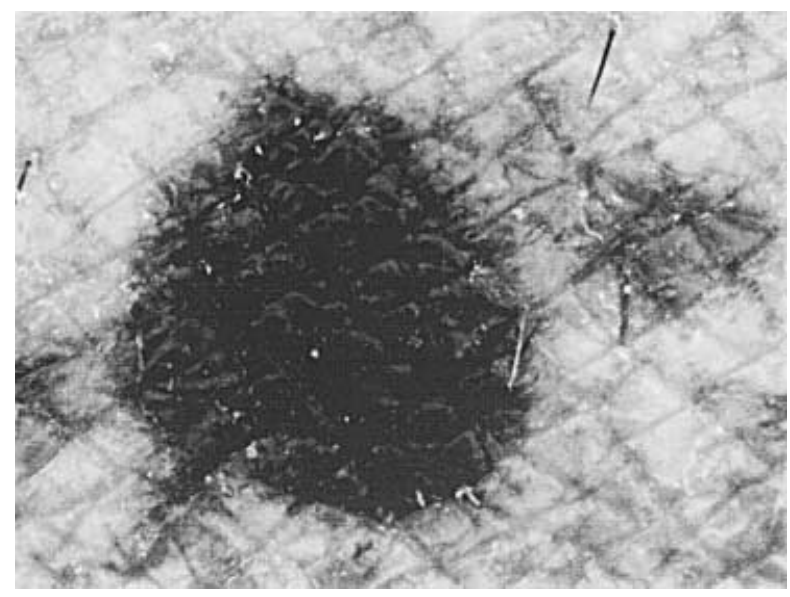

fig. 1 Appearance of actinic lentigo under ultraviolet light illumination
After completing the non-invasive colour assessments, corneomelametry was performed on cyanoacrylate skin surface strippings (CSSS). Samples were harvested from the target lentigines and the surrounding normal looking skin. They were stained under controlled conditions in a single session by the Masson's argentaffin method. Samples were placed under a photomicroscope equipped with an internal photodensitometer. The recorded values (arbitrary units), which increased with the staining intensity, were an estimate of the melanin load inside corneocytes. ${ }^{6}$ In addition, the microscopic examination allowed to rule out the diagnoses of seborrhoeic keratoses and malignant melanoma according to previously established diagnostic criteria. 16

The mean and SD were calculated for each parameter. Variations from baseline were described in percentages. Variance analysis was performed on the raw data to test the possible changes in time on the treated and untreated control sites. $P<0.05$ was considered statistically significant.

\section{Results}

Reflectance spectrophotometric measurements showed a significant decrease in the differential $\mathrm{M}$ index on the sites receiving the test formulation applications (fig. 2). Compared with baseline, the differential $\mathrm{M}$ index was reduced by $3.5 \%$ and $8.7 \%$ $(P<0.05)$ after 1 and 2 months, respectively. The same parameter remained unmodified at the control sites. No changes were yielded in time for the differential $\mathrm{E}$ index on both the treated and untreated sites.

Video image analysis under ultraviolet light showed a decrease in the areas of the solar lentigines at the site receiving the test formulation (fig. 3). The relative area of pigmentation showed a modest decrease $(-3.8 \%)$ after 1 month. It was reduced significantly $(P<0.01)$ by $17 \%$ at 2 months compared with baseline values. By contrast, no change in size was seen on the untreated lesions.

Corneomelametry performed on CSSS showed a progressive decrease in melanin load in the stratum corneum on the treated

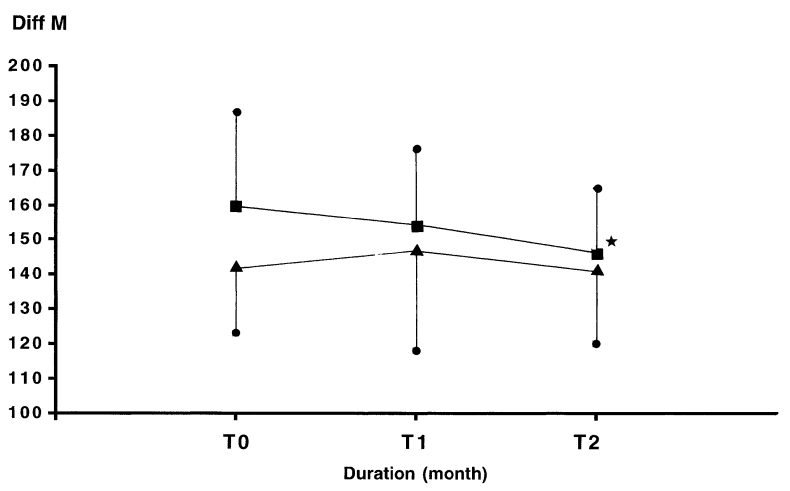

fig. 2 Evolution of the differential $M$ index (mean \pm SD) of actinic lentigines during a 2-month treatment with a $2 \%$ hydroquinone-cyclodextrin formulation (ם) or left untreated $(\boldsymbol{\Delta}) .{ }^{\star} P<0.05$ 


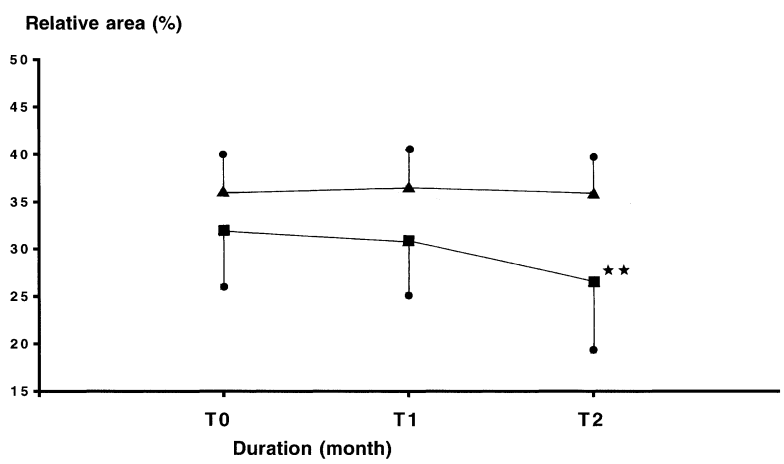

fig. 3 Evolution of the relative darkened area (mean \pm SD) of solar lentigines during a 2-month treatment with a $2 \%$ hydroquinone-cyclodextrin formulation

(ם) or left untreated $(\boldsymbol{\Delta}) .{ }^{\star \star} P<0.01$

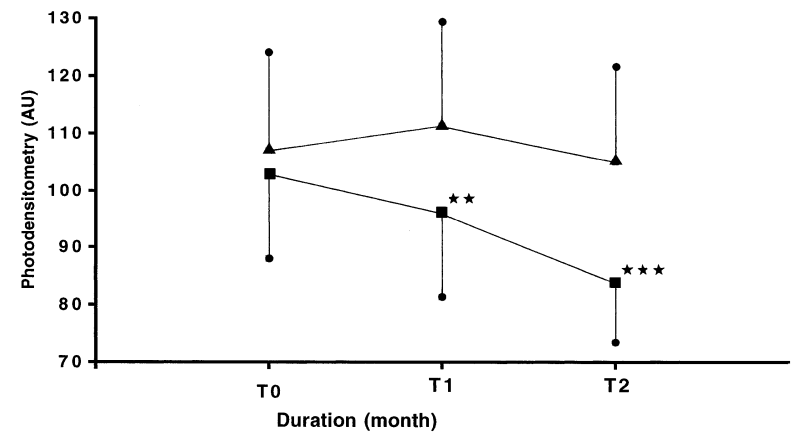

fig. 4 Evolution of the corneomelametry index (mean \pm SD of arbitrary units) of solar lentigines during a 2-month treatment with a $2 \%$ hydroquinonecyclodextrin formulation $(\boldsymbol{\square})$ or left untreated $(\boldsymbol{\Delta}) .{ }^{\star \star} P<0.01$; ${ }^{\star \star \star} P<0.001$

sites (fig. 4). Compared with baseline levels, the melanin density in the stratum corneum was reduced by $4.9 \%(P<0.01)$ and $18.6 \%(P<0.001)$ after 1 and 2 months, respectively. By contrast, no significant change was found on the control sites.

\section{Discussion}

CSSS were used for two purposes in this study. They were examined under the microscope for diagnostic purposes as previously described. 16 This method, in combination with dermoscopy, confirmed the benign nature of the lesions that were consistent with actinic lentigines. Cutaneous melanoma and pigmented seborrhoeic keratoses were ruled out.

The discovery and development of hypopigmenting compounds benefit from in vitro assays and animal models. Unfortunately, the extrapolation of the information to the in vivo human situation remains unsatisfactory. Hence, clinical trials on volunteers are critical to determine the efficacy profile of a formulation. The whitening effect of many cosmetics, overthe-counter products and dermatological formulations appears minimal on darkened age spots. 6,7 However, the effect has been reported to be improved by some combination treatments. ${ }^{17,18}$ The use of the recent cyclodextrin technology could also increase efficacy. This hypothesis was tested in the present study focused on objective and sensitive assessments of hypopigmenting effects.

The present trial relied on a three-pronged design based on quantitative objective assessments of the melanin load in different compartments of the skin. Corneomelametry was the only method showing a significant hypopigmenting effect of the test formulation after 1 months' treatment. In interpreting the data, several theoretical possibilities should be considered. The reduction in the melanin load in the stratum corneum can be the result of a reduction in the melanocyte density, an inhibition in melanin synthesis, a decreased transfer of melanosomes into keratinocytes or an increased degradation of melanosomes during the transit time of cells throughout the epidermis. ${ }^{6}$

In this study, we also used a narrow-band reflectance spectrophotometer equipped with a small-diameter probe. The melanin content was derived from the $\mathrm{M}$ index representing the changes in wavelengths of the light emitted by the diodes of the device and those remitted by the skin. ${ }^{12}$ In contrast with previous negative findings about other hypopigmenting agents, ${ }^{6}$ the presently tested formulation induced a significant decrease in the value of the differential $\mathrm{M}$ index after 2 months' treatment. The E index remained unmodified throughout the study, suggesting that the local tolerance of the topical formulation was good. Indeed, this parameter proves to be very sensitive in disclosing local cutaneous safety issues in dermo-cosmetology. ${ }^{19}$

Image analysis of the epidermal melanin content revealed under ultraviolet light illumination is a sensitive tool to disclose any hypopigmenting effect on discrete melanoderma.6,11 In general, it is less appropriate on a darkened age spot because only a faint light comes back to the skin surface. 6 Nevertheless, the present study showed a reduction in size of the treated solar lentigines after 2 months' treatment.

In conclusion, topical applications of a $2 \%$ hydroquinonecyclodextrin formulation significantly reduced the pigmentation of actinic lentigines in Asian subjects. This was demonstrated by objective assessments of the overall skin colour, and of the melanin load in the stratum corneum and in the whole epidermis. Corneomelametry appeared to be the most sensitive method for detecting the earliest lightening changes. No intolerance was noticed.

\section{References}

1 Piérard GE, Piérard-Franchimont C, Laso Dosal F et al. Pigmentary changes in skin senescence. J Appl Cosmetol 1991; 9: $57-63$.

2 Castanet J, Ortonne JP. Pigmentary changes in aged and photoaged skin. Arch Dermatol 1997; 133: 1296-1299.

3 Kameyama K, Sakai C, Kondoh S et al. Inhibitory effect of magnesium 1-ascorbyl-2-phosphate (VC-PMG) on melanogenesis in vitro and in vivo. J Am Acad Dermatol 1996; 34: 29-33.

4 Masuda M, Tejima T, Suzuki T, Imokawa G. Skin lighteners. Cosmet Toilet 1996; 111: 65-77. 
5 Gao X, Chen H, Kligman A. Topical tretinoin for photoaging. The China experience. J Appl Cosmetol 1997; 15: 77-83.

6 Hermanns JF, Petit L, Piérard-Franchimont C et al. Assessment of topical hypopigmenting agents on solar lentigines of Asian women. Dermatology 2002; 204: 281-286.

7 Miyamoto K, Takiwaki H, Hillebrand G, Arase S. Utilization of a high-resolution digital imaging system for the objective and quantitative assessment of hyperpigmented spots on the face. Skin Res Technol 2002; 8: 73-77.

8 Mishima Y, Hatta S, Ohyama Y, Inazu M. Induction of melanogenesis suppression: cellular pharmacology and mode of differential action. Pigment Cell Res 1988; 1: 367-374.

9 Dooley TP. Topical skin depigmentation agents: current products and discovery of a novel inhibitor of melanogenesis. J Dermatol Treat 1997; 8: 275-279.

10 Ortonne JP, Balotti R. Melanocyte biology and melanogenesis: what's new? J Dermatol Treat 2000; 11: S15-S26.

11 Hermanns JF, Petit L, Piérard-Franchimont C et al. Unraveling the patterns of subclinical phaeomelanin-enriched facial hyperpigmentation. Effect of depigmenting agents. Dermatology 2000; 201: 118-122.

12 Loftsson T, Olafsson JH. Cyclodextrins: new drug delivery systems in dermatology. Int J Dermatol 1998; 37: 241-246.
13 Piérard GE. EEMCO guidance for the assessment of skin colour. J Eur Acad Dermatol Venereol 1998; 10: 1-11.

14 Hermanns JF, Petit L, Hermanns-Lê T, Piérard GE. Analytic quantification of phototype-related regional skin complexion. Skin Res Technol 2001; 7: 168-171.

15 Hermanns JF, Henry F, Piérard-Franchimont C, Piérard GE. Quantification analytique du vieillissement du système mélanocytaire. Implication dans la détermination objective du risque de cancers cutanés. Ann Gerontol 2001; 15: 233-239.

16 Piérard-Franchimont C, Piérard GE. Assessment of aging and actinic by cyanoacrylate skin surface strippings. Am J Dermatopathol 1987; 9: 500-509.

17 Garcia A, Fulton JE. The combination of glycolic acid and hydroquinone or kojic acid for the treatment of melasma and related conditions. Dermatol Surg 1996; 22: 443-447.

18 Fleisher AB, Schwartzel EH, Colby SI, Altman DJ. The combination of $2 \%$-hyroxyanisole (Mequinol) and $0.01 \%$ tretinoin is effective in improving the appearance of solar lentigines and related hyperpigmented spots in two double-blind multicenter clinical studies. J Am Acad Dermatol 2000; 42: 459-467.

19 Hermanns JF, Piérard-Franchimont C, Piérard GE. Skin colour assessment in safety testing of cosmetics. An overview. Int J Cosmet Sci 2000; 22: 67-71. 